\title{
Emprego de fixador externo circular no tratamento de complicações de fraturas do rádio e ulna em cães de raças pequenas
}

\author{
Use of circular external fixator in the treatment of fracture complications \\ of radius and ulna in small breed dogs
}

\author{
Sheila Canevese Rahal ${ }^{1}$ Reinaldo dos Santos Volpi ${ }^{2}$ Khadije Hette ${ }^{1}$ \\ Luiz Carlos Vulcano $^{3}$ Renata Cianni Büttner ${ }^{1}$
}

\section{RESUMO}

O objetivo deste estudo foi avaliar o método de Ilizarov no tratamento de complicações de fraturas do rádio $e$ ulna em cães de raças pequenas. Um fixador de Ilizarov miniatura composto por anéis de alumínio e hastes de aço foi usado em três cães da raça poodle miniatura (casos 1, 2 e 3) $e$ em um pinscher (caso 4). Os cães 1 e 4 apresentavam consolidação atrasada das porções médio-distal e distal, respectivamente, devido a prévio tratamento com tala externa. Foi aplicada uma montagem constituída por dois anéis proximais e um distal. Ambas as fraturas consolidaram, sendo que a do poodle apresentou leve desvio cranial das extremidades fraturadas. Os outros dois casos (2 e 3) consistiam de fraturas previamente tratadas por procedimento cirúrgico. o caso 2 apresentava rotação lateral do membro torácico $e$ não-união do aspecto distal da diáfise radial com presença de pino intramedular e dois fios de cerclagem. O pino intramedular e um dos fios de cerclagem foram removidos e realizou-se a derrotação do foco da fratura. O aparelho foi montado como nos casos 1 e 4. A consolidação da fratura foi obtida com moderado desvio caudal do eixo ósseo. No caso 3, havia reabsorção óssea na diáfise do rádio e ulna devido ao emprego inadequado de fixador externo resina-pino. Empregou-se o transporte ósseo com o fixador de Ilizarov para induzir a regeneração óssea. Entretanto, este foi interrompido por falta de resposta. Manteve-se o fixador e o defeito ósseo foi tratado com enxerto esponjoso autólogo e biomateriais. A ulna ocupou parte do defeito segmentar do rádio. Foi possível concluir que o método de Ilizarov pode ser usado no tratamento de consolidação atrasada e não-união, mas o fixador externo circular é de difícil aplicação em cães de raças pequenas.

Palavras-chave: ortopedia, Ilizarov, cirurgia, não-união.

\begin{abstract}
The aim of this study was to evaluate the Ilizarov's method for treating complications of radius and ulna fractures in small breed dogs. A miniature Ilizarov's fixator constructed using aluminum rings and steel rods was used in three Miniature Poodles (cases 1, 2 and 3) and in one Pinscher (case 4). Because of previous treatment with splints, cases 1 and 4 showed delayed union of the mid-distal and distal aspect of the radius-ulna shaft, respectively. The frame was assembled using two proximal rings and one distal ring. Fractures in cases 1 and 4 healed completely. However, case 1 showed a slight cranial deviation of the segments in the fractured site. The other two cases (2 and 3) had complications because of surgically-treated fractures. Case 2 showed forelimb lateral rotation and nonunion of the distal aspect of the radial diaphysis associated with an intramedullary pin and two cerclage wires. The intramedullary pin and one of the cerclage wires were then removed and fracture-derotation was done. The frame was assembled as in cases 1 and 4. Fracture healing was achieved with moderate caudal deviation of the bone shaft. In case 3, bone reabsorption in diaphysis was observed due to inadequate use of pin-resin external fixator. Bone transport with the Ilizarov's fixator was used to induce bone regeneration. However, this treatment option was interrupted due to lack of response. The Ilizarov's fixator was maintained and the bone defect was treated using autogenous cancellous bone graft and biomaterials. Ulna filled out part of bone defect of the radius. It was possible to conclude that the Ilizarov's method may be used in the treatment of delayed union and nonunion, but the circular external fixator is difficult to apply in small breed dogs.
\end{abstract}

Key words: ortopedic, Ilizarov, surgery, nounion.

${ }^{1}$ Departamento de Cirurgia e Anestesiologia Veterinária, Faculdade de Medicina Veterinária e Zootecnia, Universidade do Estado de São Paulo (Unesp), Rubião Júnior s/n, 18618000, Botucatu, SP, Brasil. Email: sheilacr@fmvz.unesp.br. Autor para correspondência.

${ }^{2}$ Departamento de Cirurgia e Ortopedia, Faculdade de Medicina, Unesp Botucatu, SP, Brasil.

${ }^{3}$ Departamento de Reprodução Animal e Radiologia Veterinária, Faculdade de Medicina Veterinária e Zootecnia, Unesp, Botucatu. 


\section{INTRODUÇÃO}

O fixador externo de Ilizarov é constituído por fios tensionados unidos a uma série de anéis inteiros ou semi-anéis, que são conectados uns aos outros por hastes telescópicas ou rosqueadas (NEWSCHWANDER \& DUNST, 1989). É um aparelho com múltiplos propósitos e pode ser usado para alongar ossos, corrigir deformidades angulares ou rotacionais, bem como imobilizar fraturas (ILIZAROV, 1992). Por ser axialmente elástico, o fixador de Ilizarov difere de sistemas rígidos, tais como placas e fixadores externos tradicionais (SCHWARTSMAN et al., 1990; KUMMER, 1992).

A consolidação de uma fratura é dependente da estabilidade mecânica, do adequado suprimento sangüíneo e de estimulação. A falta de quaisquer destes fatores causa complicações (GUGENHEIM, 1998). De acordo com SCHWARTSMAN et al. (1990), os princípios cardinais para o tratamento de consolidações atrasadas e nãouniões são estabilidade, alinhamento axial, vascularidade e função. Entretanto, a mobilidade telescópica axial cíclica não rígida obtida com o fixador de Ilizarov é um importante estímulo para a consolidação óssea e deve ser utilizada de acordo com o tipo da não-união.

A não-união hipertrófica tem um suprimento sangüíneo vital na extremidade de cada osso e uma interface colagenosa densa (ARONSON, 1997). Por esta razão, a formação óssea pode ser estimulada por distração gradual da não-união, o que favorece a metaplasia do tecido fibroso desorganizado para colunas ósseas ordenadas (GUGENHEIM, 1998). A não-união atrófica requer estimulação biológica e estabilidade (SCHWARTSMAN et al., 1990). Se as extremidades ósseas não estiverem reativas, a não-união é tratada inicialmente por compressão e posterior distração (ARONSON, 1997). Além disso, pode ser executada uma corticotomia, não apenas para eqüalizar o comprimento do membro, mas também para criar estímulo biológico para osteogênese (SCHWARTSMAN et al., 1990). O transporte ósseo é outra opção (ARONSON, 1997; GUGENHEIM, 1998).

FERRETTI (1998) citou que, em pequenos animais, as estratégias mais comumente utilizadas com o fixador de Ilizarov são: distração monofocal no tratamento de não-união hipertrófica asséptica rígida e com conto viável; compressão monofocal, indicada em todos os casos de não-união (incluindo a hipertrófica, para a qual a simples estabilização seria suficiente), mas absolutamente indispensável no tratamento da não-união atrófica; compressão e subseqüente distração monofocal para não-união atrófica ou normotrófica em que a compressão tem levado à melhora do trofismo no local de não-união; distração e subseqüente compressão bifocal, também chamada de transporte ósseo, para não-união atrófica com perda óssea espontânea ou seguinte a ressecção cirúrgica de osso séptico ou necrótico.

Em virtude da dificuldade de consolidação das fraturas localizadas no antebraço, o presente trabalho teve por objetivo avaliar o método de Ilizarov no tratamento de complicações de fraturas do rádio e ulna em cães de raças pequenas.

\section{MATERIAL E MÉTODOS}

Foram utilizados quatro cães de pequeno porte (casos 1, 2, 3 e 4) com complicações na consolidação de fraturas do rádio e ulna, selecionados durante o atendimento do Serviço de Cirurgia de Pequenos Animais da Faculdade de Medicina Veterinária e Zootecnia da Unesp Botucatu (Tabela 1). Os cães 1 e 4 apresentavam consolidação atrasada das porções médio-distal e distal do rádio e ulna, respectivamente, devido a prévio tratamento com tala. Os outros dois casos (2 e 3) consistiam de fraturas que haviam sido tratadas por procedimento cirúrgico. O caso 2 apresentava não-união do aspecto distal da diáfise radial com rotação lateral do fragmento distal, presença de pino intramedular e dois fios de cerclagem. No caso 3, havia reabsorção óssea na diáfise devido ao emprego inadequado de fixador externo resina-pino. Este tinha sido aplicado duas vezes, porque, durante a intervenção, cirúrgica, ocorreu fratura no local da passagem de um dos fios transfixantes. Todos os cães tinham restrição do movimento da articulação antebraquiocárpica.

Os procedimentos cirúrgicos foram efetuados com os animais sob anestesia geral inalatória. Aplicou-se buprenorfina $\left(15 \mu \mathrm{g} \mathrm{kg}^{-1}, \mathrm{IM}\right)$ antes e 12 horas após o procedimento cirúrgico. No pós-operatório, utilizou-se flunixina meglumina (1,1mg $\mathrm{kg}^{-1}$, via subcutânea), a cada 24 horas, por até quatro dias. Durante a evolução do tratamento, os cães que manifestaram sinais de dor receberam buprenorfina, flunixina meglumina ou carprofeno $\left(4 \mathrm{mg} \mathrm{kg}^{-1}\right.$, via oral).

Aplicou-se um mini aparelho de Ilizarov ${ }^{\mathrm{a}}$, com anéis confeccionados de alumínio e demais componentes de aço inoxidável (hastes rosqueadas, fios transósseos, parafusos fixa fio, parafusos tendefio, roscas, parafuso de conexão, bandeiras etc.). Foi aplicada montagem constituída por dois anéis proximais e um distal ao foco da fratura. Nos anéis proximais, foram colocados dois fios em cada anel $(1 \mathrm{~mm}$ de

Ciência Rural, v.35 n. 5, set-out, 2005. 
Tabela 1 - Identificação do cão, tratamento prévio e tempo de evolução, tipo de lesão óssea, tempo de permanência do fixador circular de Ilizarov, resultado funcional.

\begin{tabular}{|c|c|c|c|c|}
\hline Identificação do cão & $\begin{array}{l}\text { Tratamento prévio e tempo } \\
\text { de evolução }\end{array}$ & Tipo de lesão & $\begin{array}{l}\text { Tempo de permanência } \\
\text { do fixador circular }\end{array}$ & $\begin{array}{l}\text { Resultado } \\
\text { funcional }\end{array}$ \\
\hline $\begin{array}{l}\text { Poodle, } 2 \text { anos, fêmea, } \\
2,4 \mathrm{~kg} \\
\text { (caso 1) }\end{array}$ & $\begin{array}{l}\text { Imobilização com tala por } 3 \\
\text { meses }\end{array}$ & $\begin{array}{l}\text { Consolidação atrasada de fratura oblíqua } \\
\text { curta da porção médio-distal de rádio e } \\
\text { ulna direitos, com desvio do eixo ósseo }\end{array}$ & 5 meses & excelente \\
\hline $\begin{array}{l}\text { Poodle, } 6 \text { anos, macho, } \\
2 \mathrm{~kg} \\
\text { (caso 2) }\end{array}$ & $\begin{array}{lr}\text { Imobilização interna } & \text { com } \\
\text { pino intramedular } & \text { e } \\
\text { cerclagem por } 5 \text { meses } & \end{array}$ & $\begin{array}{l}\text { Não-união do terço distal da diáfise de } \\
\text { rádio e ulna esquerdos com rotação lateral } \\
\text { do fragmento distal. Reação periosteal. } \\
\text { Presença de pino intramedular atingindo } \\
\text { articulação úmero-radial e dois fios de } \\
\text { cerclagem, um proximal e outro distal ao } \\
\text { foco de fratura }\end{array}$ & 6 meses & excelente \\
\hline $\begin{array}{l}\text { Poodle, } 1 \text { ano, macho, } \\
2,5 \mathrm{~kg} \\
\text { (caso 3) }\end{array}$ & $\begin{array}{l}\text { Imobilização com fixador } \\
\text { externo por } 2 \text { meses }\end{array}$ & $\begin{array}{l}\text { Falha segmentar devido reabsorção óssea } \\
\text { na diáfise médio-distal de rádio e ulna } \\
\text { esquerdos }\end{array}$ & 4 meses & satisfatório \\
\hline $\begin{array}{l}\text { Pinscher, } 2 \text { anos, fêmea, } \\
1,7 \mathrm{~kg} \\
\text { (caso } 4 \text { ) }\end{array}$ & $\begin{array}{l}\text { Imobilização com tala por } 2 \\
\text { meses }\end{array}$ & $\begin{array}{l}\text { Consolidação atrasada de fratura completa } \\
\text { transversa, distal, de rádio e ulna direitos, } \\
\text { com desvio do eixo ósseo }\end{array}$ & 2,5 meses & excelente \\
\hline
\end{tabular}

diâmetro) com ângulo de intersecção de $60^{\circ}$ a $90^{\circ}$, dependendo da anatomia da região. Estes foram fixados aos anéis por meio de parafusos fixa fio ou tendefio e tensionados com tensor de fio manual. No caso 2, utilizou-se um fio em bandeira junto ao anel distal. $\mathrm{O}$ foco de fratura foi manipulado por acesso aberto limitado (casos 1, 2 e 4) ou de forma fechada (caso 3) e a princípio não foi utilizado enxerto esponjoso. No caso 3 , foi possível remover o pino intramedular e apenas um dos fios de cerclagem. Além disso, o foco de fratura foi derrotacionado antes da aplicação do fixador. No caso 4, o aparelho foi montado para realização do transporte ósseo. Para tanto, foi efetuada osteotomia subperiosteal na porção proximal do rádio e ulna, entre os anéis proximal e medial, de forma a produzir um fragmento ósseo transportável. Após um período de latência de sete dias, o fragmento foi transportado por movimentação do anel medial em direção ao distal utilizando um protocolo de 0,5 a $1 \mathrm{~mm}$ por dia, no ritmo de $0,25 \mathrm{~mm}$ a cada 6 ou 12 horas.

A evolução da consolidação de fratura foi acompanhada por meio de radiografias seriadas (Figuras 1 e 2). A função do membro, após a remoção do fixador, foi graduada de acordo com a escala de FOX (1995): excelente, função normal do membro; bom, leve claudicação apenas após exercício; satisfatório, leve a moderada claudicação mas consistente suporte de peso; ruim, nenhum suporte de peso.

\section{RESULTADOS}

A aplicação do aparelho foi difícil em virtude do pequeno porte dos animais. Todos os cães adaptaram-se ao fixador, com apoio do membro ao solo já na primeira semana de pós-cirúrgico. Nos casos 1 e 4 (Figura 2), o alinhamento do foco de fratura não estava adequado no pós-operatório imediato e foi corrigido periodicamente pela movimentação dos anéis proximal e distal de forma excêntrica. Ambas as fraturas consolidaram, e apenas a do caso 1 apresentou leve desvio cranial das extremidades fraturadas (Tabela 1). No caso 2, os anéis foram movimentados longitudinalmente de forma periódica para aproximação e compressão das extremidades fraturadas. A consolidação da fratura foi obtida com moderado desvio caudal do eixo ósseo. Para maior proteção após a remoção do fixador, os antebraços dos cães 1, 2 e 4 foram mantidos por curto período de tempo com tala que permitia total apoio da mão ao solo.

No caso 3, o transporte ósseo precisou ser interrompido um mês após o procedimento cirúrgico, já que não havia sinais radiográficos de regeneração óssea. Optou-se por realizar compressão progressiva do local de osteotomia, movimentando o anel proximal em direção ao anel medial. Em virtude da ausência de produção óssea, o fixador de Ilizarov foi mantido e o defeito segmentar tratado aos 60 dias do procedimento cirúrgico inicial com enxerto esponjoso autólogo, colhido da asa do ílio, e aos 100 dias com biomateriais de origem bovina (BMPs adsorvidas a hidroxiapatita, aglutinante de colágeno liofilizado em grânulos e osso cortical inorgânico microgranular) ${ }^{\mathrm{b}}$ envoltos em uma membrana reabsorvível de cortical óssea descalcificada liofilizadac.

Removeu-se o fixador oito meses após a cirurgia. Os biomateriais foram progressivamente

Ciência Rural, v. 35, n. 5, set-out, 2005. 


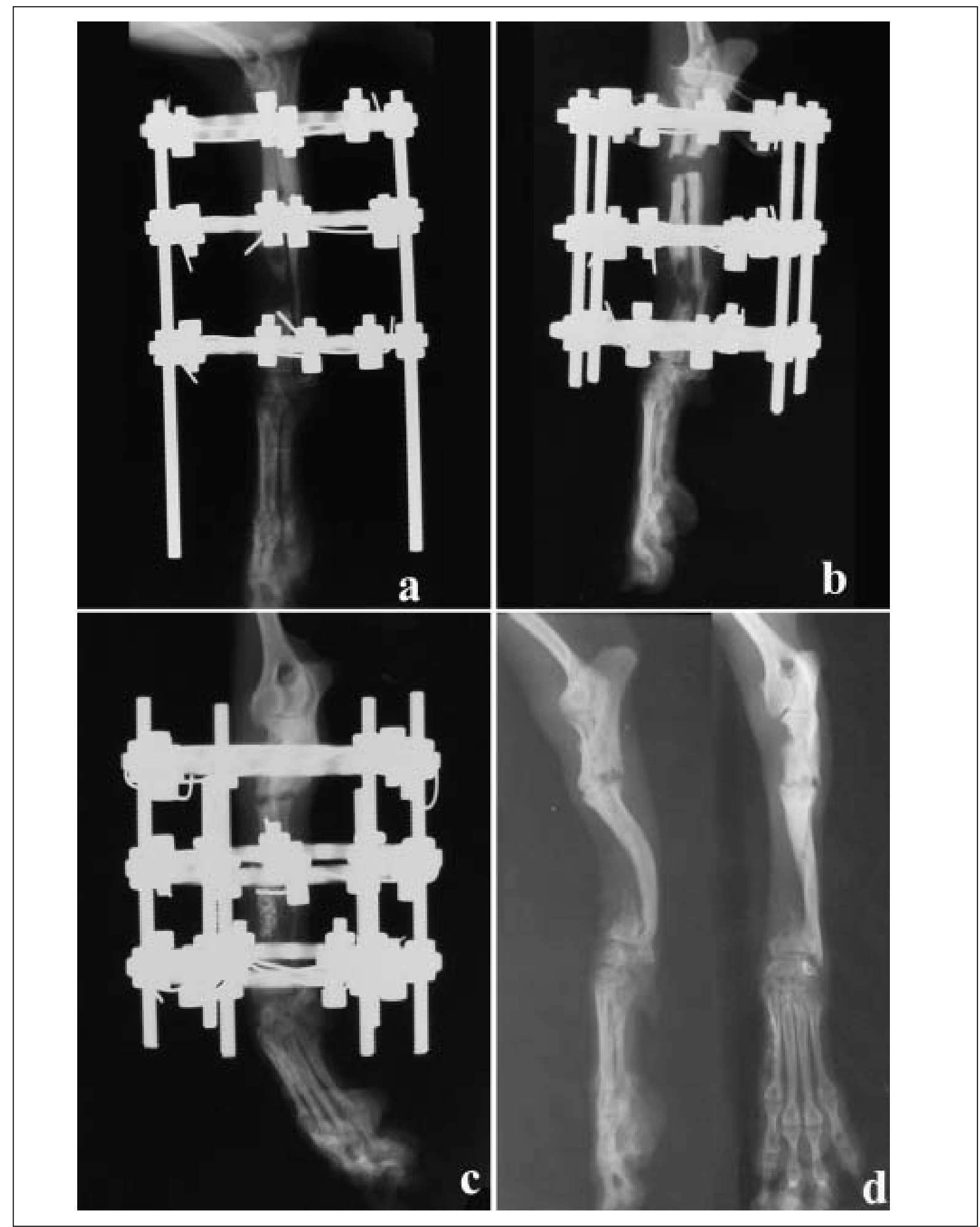

Figura 1 - Evolução do caso 3. Aspectos radiográficos do rádio e ulna em posição lateral (a, b) ou lateral oblíqua (c): (a) trans-cirúrgico mostrando a falha óssea segmentar extensa e alinhamento ósseo antes da osteotomia; (b) sete dias de transporte ósseo; (c) aplicação de biomateriais de origem bovina na falha segmentar, 100 dias após o procedimento cirúrgico inicial. (d) Radiografias lateral e craniocaudal do antebraço 2 anos após a remoção do fixador. Nota-se a ulna ocupando o espaço do rádio e no local de osteotomia apenas a consolidação do rádio.

Ciência Rural, v.35 n. 5, set-out, 2005. 

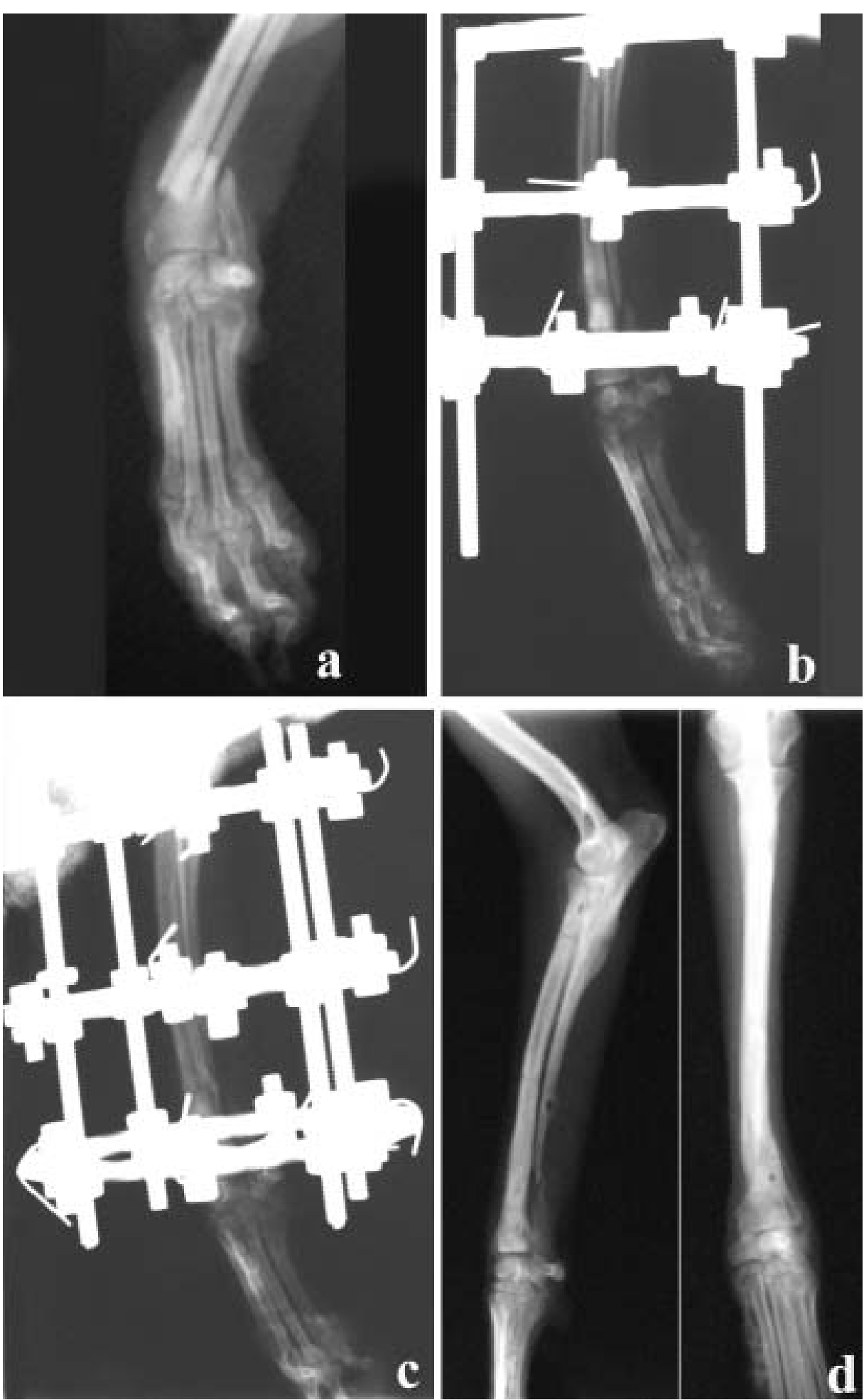

Figura 2 - Evolução do caso 4. Aspectos radiográficos do rádio e ulna: (a) pré-operatório em posição craniocaudal; (b) trans-operatório, em posição lateral, mostrando discreta sobreposição da extremidades fraturadas do rádio (c) 30 dias de pós-operatório, em posição lateral oblíqua; (d) 60 dias após a remoção do fixador, mostrando consolidação das extremidades fraturadas sem formação de calo externo, em posições lateral e craniocaudal. 
reabsorvidos, a ulna se espessou e ocupou parte do defeito segmentar do rádio. No local da osteotomia, ocorreu consolidação apenas do rádio, e não havia mobilidade à palpação. Além disso, observou-se sinostose entre rádio e ulna em sua porção proximal (Figura 1). Recomendou-se não utilizar qualquer método de imobilização externa, porém, devido ao comportamento ativo do cão, o proprietário optou por mantê-lo com tala desenvolvida de forma a manter as articulações do cotovelo e antebraquiocárpica livres. $\mathrm{O}$ animal adaptou-se bem a essa condição.

O resultado funcional, após a remoção do fixador, foi considerado excelente nos casos 1, 2 e 4, e satisfatório no 3 . $\mathrm{O}$ caso 1 foi acompanhado por mais oito meses, quando veio a óbito após briga com outro cão. Dois anos e meio após a cirurgia, o cão 4 sofreu uma queda e fraturou o mesmo membro, porém na porção proximal do rádio e ulna. Utilizou-se fixador externo resina acrílica-pino com evolução excelente. $\mathrm{O}$ caso 2 foi acompanhado por mais quatro meses e o caso 3, por três anos. Ambos mantiveram o mesmo quadro funcional.

\section{DISCUSSÃO}

A alta prevalência de consolidação retardada e não-união após tratamento de fraturas do antebraço de cães de raças pequenas é reconhecida há anos, porém a causa não está totalmente esclarecida (WATERS et al., 1993; MUIR, 1997). Dentre os métodos de imobilização, as talas e os pinos intramedulares, por serem instáveis mecanicamente, são os que mais favorecem o desenvolvimento das complicações (LAPPIN et al., 1983; WATERS et al., 1993), como verificado nos casos 1, 2 e 4 . Além disso, conforme o método de inserção, o pino intramedular pode danificar a articulação antebraquiocárpica (WATERS et al., 1993; MUIR, 1997), ou mesmo a úmero-radial, como no caso 2. As placas metálicas e o fixador esquelético externo $\mathrm{K}$-E ou de resina-pino são tradicionalmente os métodos mais indicados tanto para minimizar como para tratar essas complicações (LAPPIN et al., 1983; EGER, 1990; WATERS et al., 1993; LARSEN et al., 1999). Entretanto, quando mal aplicados, podem induzir lesões de difícil resolução, como observado no caso 3 , em que o uso inadequado dos pinos de transfixação induziu uma nova fratura e o processo de reabsorção óssea.

No presente experimento, optou-se pelo uso do fixador de Ilizarov, por apresentar características mecânicas próprias que permitem estratégias diversas dos métodos clássicos de osteossíntese (NEWSCHWANDER \& DUNST, 1989;
SCHWARTSMAN et al., 1990; KUMMER, 1992). Nos casos 1 e 4, por exemplo, utilizou-se a movimentação assimétrica dos anéis para a correção do alinhamento ósseo. Embora possam ser usadas estratégias melhores com o fixador humano (ILIZAROV, 1992), essa foi a única possível no presente experimento, devido ao tamanho do fixador e pela limitação dos elementos secundários. No caso 2, foi utilizada a compressão periódica do foco de fratura, que é uma das opções indicada para o tratamento de não-união (FERRETI, 1998). Contudo, a lesão evoluiu de forma lenta, necessitando longo tempo de permanência com o fixador. A capacidade regenerativa óssea possivelmente estava comprometida pela lesão do suprimento sangüíneo medular, maior fonte de nutrição óssea, devido à presença do pino intramedular, e pela permanência de um dos fios de cerclagem.

O enxerto esponjoso autólogo não foi utilizado como primeira opção de tratamento, porque segundo Ilizarov ele não seria necessário (SCHWARTSMAN et al., 1990). Contudo, pela evolução dos presentes casos clínicos, em especial nos casos 1 e 2, a sua capacidade osteogênica e osteoindutiva seria um fator importante para estimular a consolidação óssea e reduzir o tempo de tratamento.

O transporte ósseo é outra forma de utilização do fixador de Ilizarov que permite correção de falhas segmentares extensas por regeneração óssea no trajeto do fragmento ósseo transportado (ARONSON, 1997; FERRETI, 1998; GUGENHEIM, 1998). Esse método já foi descrito com relativo sucesso, tanto clínica como experimentalmente, em cães de porte médio e grande (LESSER, 1994; DEGNA et al., 2000; RAHAL, 2002; RAHAL et al., 2003). As complicações citadas com a técnica foram associadas ao desvio do segmento transportado durante o seu trajeto e a consolidação vagarosa ou ausente na área de contato entre o fragmento ósseo transportado e a extremidade óssea fraturada (RAHAL, 2002). Isso diferiu do caso 3, em que não foi possível induzir a regeneração óssea no defeito segmentar. Algumas hipóteses podem ser sugeridas, tais como: a capacidade osteogênica diminuída dos cães de raças pequenas em comparação aos de raças grandes (WATERS et al., 1993; MUIR, 1997); a necessidade de período de latência, freqüência e ritmo do transporte mais vagaroso para cães de pequeno porte; a inviabilização da regeneração óssea pela gravidade da lesão prévia.

Por outro lado, vale salientar que o fragmento transportado manteve-se viável e a absorção óssea não progrediu. $\mathrm{O}$ emprego do enxerto esponjoso autólogo bem como o de biomateriais também não conseguiu induzir a formação óssea na 
falha segmentar, mas provavelmente contribuiu para que a ulna se espessasse e ocupasse parte do defeito radial. Embora o resultado final não tenha sido o esperado, evitou-se a amputação do membro, que, muitas vezes, é a solução final em complicações das fraturas do rádio e ulna com qualidade óssea ruim (WATERS et al., 1993).

\section{CONCLUSÃO}

Foi possível concluir que o método de Ilizarov pode ser usado no tratamento de consolidação atrasada e não-união, mas o fixador externo circular é de difícil aplicação em cães de raças pequenas.

\section{FONTES DE AQUISIÇÃO}

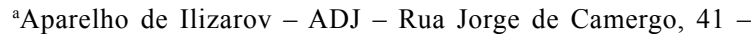
Campinas, SP.

${ }^{\mathrm{b}}$ GEN-PRO, GEN-COL, GEN-OX - Baumer S.A. - Divisão Biomateriais - Av. Pref. Antonio Tavares Leite, 181 - Parque da Empresa, 13800-000 - Mogi Mirim, SP

${ }^{\mathrm{c} G E N-D E R M ~-~ B a u m e r ~ S . A . ~-~ D i v i s a ̃ o ~ B i o m a t e r i a i s ~-~ A v . ~ P r e f . ~}$ Antonio Tavares Leite, 181 - Parque da Empresa, 13800-000

- Mogi Mirim, SP

\section{AGRADECIMENTOS}

Os autores agradecem à Fundação de Amparo à Pesquisa do Estado de São Paulo (FAPESP) pelo apoio financeiro na apresentação deste trabalho no $29^{\text {th }}$ World Small Animal Veterinary Association (WSAVA).

\section{REFERÊNCIAS}

ARONSON, J. Limb-lengthening, skeletal reconstruction, and bone transport with the Ilizarov method. J Bone J Surg (Am), v.79-A, n.8, p.1243-1258, 1997.

DEGNA, M.T. et al. Bone transport osteogenesis for limb salvage. Vet Comp Orthop Traumatol, v.13, p.18-22, 2000.

EGER, C.E. A technique for the management of radial and ulnar fractures in miniature dogs using transfixation pins. J Small Anim Pract, v.31, p.377-387, 1990.

FERRETTI, A. Fracture, nonunion and deformity treatment with the Ilizarov method. In: EUROPEAN FECAVA SCIVAC
CONGRESS, 4., 1998, Bologna, Italy. Proceedings... Bologna : FECAVA, 1998. p.471-476.

GUGENHEIM, J.J. The Ilizarov method. Orthopedic and soft tissue applications. Clin Plastic Surg, v.25, n.4, p.567578,1998 .

FOX, S.M. et al. Antebrachial deformities in the dog: treatment with external fixation. J Small Anim Pract, v.36, n7, p.315320, 1995.

ILIZAROV, G.A. Transosseous osteosynthesis. Berlim : Springer-Verlag, 1992. $800 \mathrm{p}$.

KUMMER, F.J. Biomechanics of the Ilizarov external fixator. Clin Orthop, n.280, p.11-14, 1992.

LAPPIN, M.R. et al. Fractures of the radius and ulna in the dog. J Am Anim Hosp Assoc, v.19, p.643-650, 1983.

LARSEN, L.J. et al. Bone plate fixation of distal radius and ulna fractures in small- and miniature-breed dogs. J Am Anim Hosp Assoc, v.35, p.243-250, 1999.

LESSER, A.S. Segmental bone transport for the treatment of bone deficits. J Am Anim Hosp Assoc, v.30, p.322-330, 1994.

NEWSCHWANDER, G.E.; DUNST, R.M. Limb lengthening with the Ilizarov external fixator. Orthop Nursing, v.8, n.3, p.15-21, 1989.

MUIR, P. Distal antebrachial fractures in toy-breed dogs. Comp Cont Ed Practicing Vet, v.19, n.2 p.137-145, 1997.

RAHAL, S.C. Comparação entre transporte ósseo e encurtamento agudo seguido de alongamento do membro, pelo método de Ilizarov, para o tratamento de perdas ósseas segmentares extensas da tíbia. Estudo experimental em cães. 2002. 98f. Tese (livre-docência) - Faculdade de Medicina Veterinária e Zootecnia, Campus de Botucatu, Universidade Estadual Paulista "Júlio de Mesquita Filho".

RAHAL, S.C. et al. Large segmental radius and ulna defect treated by bone transportation with the Ilizarov technique. Australian Vet J, v.81, n.11, p.15-18, 2003.

SCHWARTSMAN, V. et al. Tibial nonunions. Treatment tactics with the Ilizarov method. Orthop Clin North Am, v.21, n.4, p.639-653, 1990.

WATERS, D.J. et al. Treatment of common forelimb fractures in miniature- and toy-breed dogs. J Am Anim Hosp Assoc, v. 29, p. $442-448,1993$. 